\title{
An Inexpensive Automatic Sampler with Static Chambers for Nitrous Oxide Emission Measurement
}

\author{
Suduan Gao, Aileen Hendratna, and Tom Pflaum
}

\begin{abstract}
Static flux chambers are often used to determine emission flux of gases such as greenhouse gas nitrous oxide $\left(\mathrm{N}_{2} \mathrm{O}\right)$. However, the sampling process is laborious especially when many treatments/plots are included for measurements to compare treatment effects in the effort to develop mitigation strategies. To solve this problem, we constructed an automatic sampler (autosampler) at low cost, simple to operate, and easy maintenance and used it with static chambers to sample $\mathrm{N}_{2} \mathrm{O}$ emissions. The construction involves mechanical work including mainly woodworking for building a chassis (mounting board), syringe mounting block, and servo mounting block, and electronics for the controller involving hardware assembly, soldering, and programming to control the operation of the sampler. This paper provides the detailed information and instructions as well as price of materials for the construction of the sampler with the flexibility for modification to meet various research needs. The samplers were used to measure $\mathrm{N}_{2} \mathrm{O}$ emissions in a pomegranate field demonstrating improved sampling efficiency. The results illustrated treatment differences with much higher flux from surface drip irrigation than that from subsurface drip irrigation.
\end{abstract}

Index Terms-Greenhouse gas, emission flux, nitrogen fertilizer, drip irrigation.

\section{INTRODUCTION}

Chamber methods have been used often to measure gas emissions such as nitrous oxide $\left(\mathrm{N}_{2} \mathrm{O}\right)$ because of easy operation and less expensive equipment. Flux chambers can be categorized into two types: static (or closed, passive) and dynamic (or flow-through, active). The latter is usually more complicated to construct and operate [1]. Due to the flexibility and easy sampling procedures as well as data processing, static flux chambers are still very popular and used widely. Livingston and Hutchinson [2] reviewed and discussed many of the chamber types. The drawback of the static chamber method is that sampling can be laborious because for each flux measurement, multiple samples need to be collected over a short period of time during an initial linear increase of $\mathrm{N}_{2} \mathrm{O}$ concentration inside the chamber. The amount of sampling becomes so great that manual sampling can no longer meet the work demand. An automatic sampler can increase significantly data collection efficiency and often improve the accuracy and precision in measurements by eliminating human errors in controlling sampling time.

Manuscript received March 30, 2016; revised July 14, 2016. This work was supported by the U.S. Department of Agriculture, Agricultural Research Service (ARS). The research was conducted at the San Joaquin Valley Agricultural Sciences Center (SJVASC), Water Management Research unit, USDA-ARS, Parlier, CA, USA.

The authors are all with the USDA-ARS, Parlier, CA, USA (e-mail: suduan.gao@ars.usda.gov, brasscuzn@comcast.net).
Although the chambers can be further equipped with other instrumentation or detectors for in-situ measurement [3] they are often expensive and not practical for many researchers whose research funds are limited. The purpose of this research is to build an automatic sampler to significantly improve the efficiency for gas sampling that is often handled manually by many researchers with static flux chambers.

Ginting et al. [4] has constructed an automatic sampler with static chambers for greenhouse gas emission measurement. While attempting to construct the sampler described by Ginting et al. [4], we realized that the sampler needed to be modified based on available resources. As a result, the sampler we constructed was modified significantly from Ginting's design using materials available locally or purchased easily. We believe the information will provide readers with the flexibility to construct their own sampler that will meet their sampling needs. Our main purpose is to summarize our construction of the automatic sampler in this paper. Differences or similarities in the samplers between ours and that from Ginting's design are described and field measurements showing treatment effects are reported.

\section{CONSTRUCtion OF AUtOMATIC SAMPLER FOR $\mathrm{N}_{2} \mathrm{O}$ EMISSION SAMPLING WITH STATIC CHAMBERS}

We designed the gas autosampler to be simple to use, low cost, and constructed in house. The autosampler designed by Ginting et al. [4] served as the starting point. However, we made four major modifications. 1. Wood was selected for the construction material instead of Plexiglas ${ }^{\circledR}$ used by Ginting $e t$ al. [4] because wood working tools and qualified personnel were available. The advantage of using wood is its flexibility for making changes that allow researchers to modify the design to meet their requirements in sampling. 2 . We used a chassis (mounting board) to replace the box with lid design used by Ginting et al. [4]. The trigger release mechanism of the autosampler was modified from that of Ginting et al. In Ginting's design, a BS1 Basic Stamp ${ }^{\circledR}$ controlled transistors, which activated reed relays, and then energized the Tamiya ${ }^{\circledR}$ worm gear boxes. When the program energized the circuit for 3 seconds, the Tamiya ${ }^{\circledR}$ worm gear box would turn the output shaft 1.4 to 2.2 revolutions. In our design, however, a series of pulses was sent to the Futaba ${ }^{\circledR}$ servo and the servo rotated until it was in the correct position. The Tamiya ${ }^{\circledR}$ worm gear box will rotate as long as it is connected to the power and its final position is indeterminate, while the Futaba ${ }^{\circledR}$ servo will rotate to the desired position and stop. 4. A completely new electronic controller was assembled using a Programmable Interface Controller (PIC®) 16F628A chip with additional components: a $5 \mathrm{MHz}$ crystal, a 5 volt regulator, a pushbutton 
switch, capacitors, resistors, light emitting diodes, a dual inline package (DIP) socket, Molex® (Lisle, IL, USA) KK series headers, and bus bar wire. For comparison, Ginting et al. [4] used the BS1 Basic Stamp® that consisted of a PIC® 16FC56A chip with additional components: EEPROM (electrically erasable programmable read-only memory), 4 $\mathrm{MHz}$ resonator, 5 volt regulator, resistors, capacitor, and voltage detector. To program the BS1 Basic Stamp® it was connected to a computer running Windows ${ }^{\circledR}$ using the DB-9 serial port. To program our PIC 16F628A PIC® chip, the EPIC тм Plus for Windows PIC MCU Programmer was connected (using the DB-25 parallel printer port) to a computer running Windows ${ }^{\circledR}$, and then the PIC $₫$ chip was removed from the DIP socket and placed in the programmer. After loading the hex file into the PIC chip, the PIC chip was removed from the programmer and reinserted into the DIP socket of the controller.

Our gas autosampler was designed to automatically collect four gas samples sequentially in four separate syringes. One way check valves (Male x Female Luer Check Valve, Item \# AP13CVSXFSL, ARK-PLAS Products Inc., Flippin, AR, USA) were fitted to the end of the syringes to prevent any loss of gas sample after withdrawal. The gas samples were collected at $0,30,60$, and 90 minutes after the gas autosampler was started. These sampling times were determined previously when $\mathrm{N}_{2} \mathrm{O}$ concentration increase was linear upon chamber closure. The collection times can be changed by reprogramming the chip.

To summarize, the automatic gas sampler was constructed of four main components: 1) the chassis (mounting board), 2) syringe mounting blocks, 3) servo mounting blocks, and 4) the controller fastened to the chassis. All parts needed for construction of the sampler are provided in Table I. A measured drawing and a photo of the final autosampler are shown in Fig. 1. The work to construct the gas autosampler is described below in Mechanical and Electronics.

\section{A. Mechanical}

The mechanical work for the sampler involved assembly of three main wood structures: the chassis, the syringe mounting block, and the servo mounting blocks. The majority of the wooden pieces were constructed of $17.5 \mathrm{~mm}$ thick $\mathrm{AB}$ grade softwood plywood. A small amount of $19.1 \mathrm{~mm}$ thick pine and birch was used in the servo mounting blocks. It should be noted that the gas autosampler was constructed with lumber and hardware available in the USA, so the dimensions for most materials were originally in Imperial units, but converted to metric equivalents to meet the journal requirement.

\section{1) Chassis}

The chassis was a piece of $17.5 \mathrm{~mm}$ thick plywood (330 $\mathrm{mm}$ by $533 \mathrm{~mm}$ ). At the two corners opposite from the syringe mounting block, $16 \mathrm{~mm}$ diameter holes were drilled and pieces of $16 \mathrm{~mm}$ diameter wooden dowels were glued in. The length of the dowels was such that $51 \mathrm{~mm}$ was exposed above the chassis. These dowels allow the gas autosamplers to be stacked or easily picked up to be placed in a container.

A 3 terminal European style barrier strip for connecting low voltage (12 volt) electrical wires (made by cutting up a larger barrier strip) was attached to the chassis. Two $0.82 \mathrm{~mm}^{2}$ stranded insulated wires were used to connect one side of the barrier strip to a 12 volt lead acid rechargeable battery via the Molex ${ }^{\circledR}$ Power Connectors. Two $0.20 \mathrm{~mm}^{2}$ stranded insulated wires were connected to the opposite side of the barrier strip to bring power to the controller.

\section{2) Syringe mounting block}

The syringe mounting block starts with three layers of 17.5 $\mathrm{mm}$ thick plywood that were glued together with water resistant glue (Titebond ${ }^{\circledR}$, Franklin International, Columbus, Ohio, USA). The $52.4 \mathrm{~mm}$ thick block was then trimmed to a height of $50.8 \mathrm{~mm}$ and a length of $533 \mathrm{~mm}$, which was equal to the width of the chassis. Using a drill press, holes were drilled for the syringes, trigger rods, syringe retaining screws, and mounting screws. The wood above the hole for the syringe was removed to form a " $U$ " shaped opening in the syringe mounting block.

Fasteners are described with the diameter followed by the length. The syringe was retained by two $5 \mathrm{~mm}$ fender washers ( $31.8 \mathrm{~mm}$ outside diameter) held in place by two hex head self tapping screws $5 \mathrm{~mm} \times 25.4 \mathrm{~mm}$ screwed into the syringe mounting block. Two $5 \mathrm{~mm}$ regular washers were placed on the screw between the fender washer and the syringe mounting block. The screws were adjusted to allow the syringe flange to be held securely and yet loose enough to allow for manual insertion and removal of the syringe. The 3 $\mathrm{mm}$ diameter brass trigger rod had a right angle bend and was retained by shaft collars (Du-bro model 597, Wauconda, IL, USA). The small set screws of the shaft collars were replaced with suitably sized socket headed cap screws. The syringe mounting block was attached to the chassis by fine thread drywall screws $4 \mathrm{~mm} \times 63.5 \mathrm{~mm}$. Flat head wood screws could also be used.

\section{3) Servo mounting block}

The servo mounting block was started with a $36.5 \mathrm{~mm} \times$ $136.5 \mathrm{~mm}$ piece of $17.5 \mathrm{~mm}$ thick plywood that had two 3.2 $\mathrm{mm}$ diameter mounting holes drilled into it. To insure proper spacing of the Futaba ${ }^{\circledR}$ servo to the mounting blocks, the round rubber servo mount grommets (Futaba ${ }^{\circledR}$ model FSH10, Mobara, Chiba Prefecture, Japan) were installed in the servo mounting ears. In addition, the eyelets (Du-bro model 114, Wauconda, IL, USA) were inserted into the grommets. With the servo and $17.5 \mathrm{~mm}$ thick plywood on edge, a $20.6 \mathrm{~mm} \mathrm{x}$ $9.5 \mathrm{~mm}$ piece of $19.1 \mathrm{~mm}$ thick birch was held against the Futaba ${ }^{\circledR}$ Servo and the block was glued to the $17.5 \mathrm{~m}$ thick plywood. The birch block was located $13.5 \mathrm{~mm}$ from the end of the plywood. After the glue was dry, a $38.1 \mathrm{~mm}$ x $25.4 \mathrm{~mm}$ piece of $19.1 \mathrm{~mm}$ thick pine wood was held against the Futaba ${ }^{\circledR}$ servo and the block was glued to the $17.5 \mathrm{~mm}$ thick plywood. Pilot holes were then drilled $(2.0 \mathrm{~mm}$ for hardwood or $1.1 \mathrm{~mm}$ for softwood) and the servo mounting screws and washers (Du-bro model 114, Wauconda, IL, USA) were used to attach the servo to the servo mounting block. The details of servo mounting hardware can be found at http://www.rcuniverse.com/forum/beginners-85/9285148-ser vo-mounting-tips-needed.html.

Close to the syringe mounting block, the servo mounting block was attached to the chassis by a Phillips round head metal screw $3.5 \mathrm{~mm} \times 31.8 \mathrm{~mm}$ with a $3.5 \mathrm{~mm}$ washer beneath 
the head of the screw. Close to the spring anchors, the servo mounting block was attached to the chassis by a hex head metal screw $3.5 \mathrm{~mm} \times 31.8 \mathrm{~mm}$ with a $3.5 \mathrm{~mm}$ washer beneath the head of the screw. The location of the servo mounting block must clear the syringe plunger and the trigger rod must be retained securely, but not too tightly. If necessary the holes in the servo mounting block can be elongated to allow for adjustment.

Each sampling module consists of a section of syringe mounting block and a servo mounting block screwed to the chassis. The top and front views of a sampling module are provided in Fig. 2.
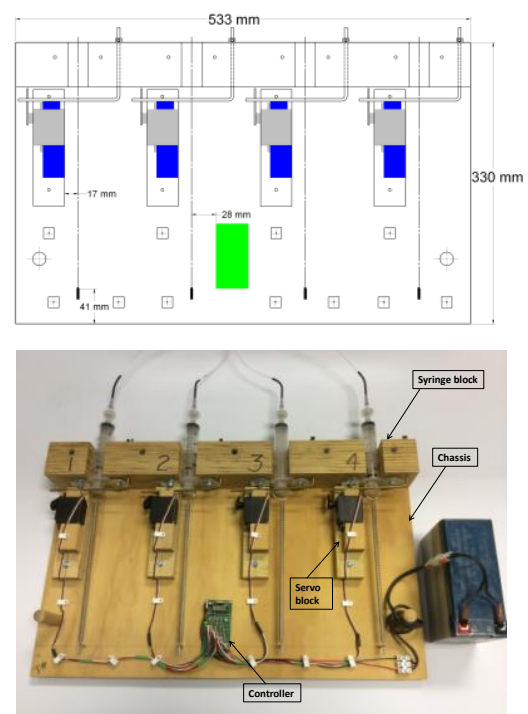

Fig. 1. Complete gas autosampler: Top, measured drawing; bottom, photo.

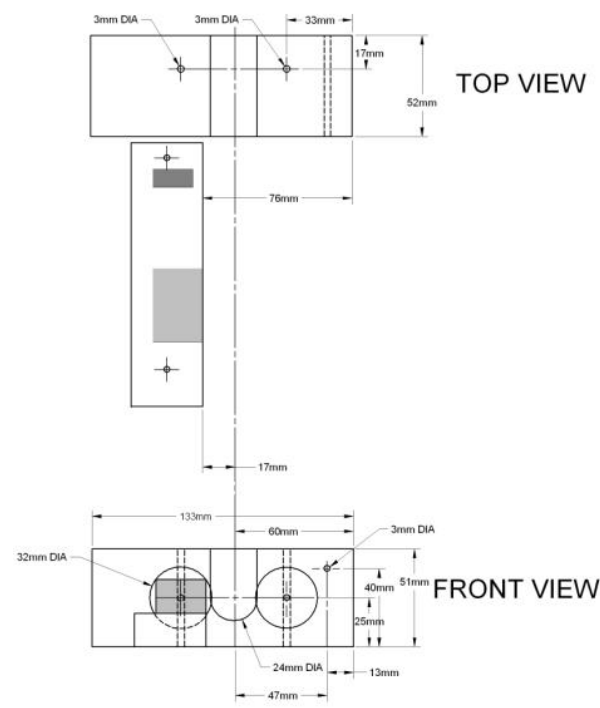

Fig. 2. Measured drawing of a sampling module.

\section{B. Electronics}

\section{1) Assembly of the controller}

The controller of the autosampler consisted of a Microchip ${ }^{\circledR}$ (Chandler, AZ, USA) 16F628A PIC® Chip, a 5 $\mathrm{MHz}$ crystal, a 5 volt regulator, a pushbutton switch, capacitors, resistors, light emitting diodes, a DIP socket, Molex® (Lisle, IL, USA) KK series headers, bus bar wire, a prototyping circuit board, and a 12 volt battery. Detailed information on the 16F628A PIC® Chip can be found at Microchip ${ }^{\circledR}$ website
(http://www.microchip.com/wwwproducts/Devices.aspx?pro duct=PIC16F628A). A diagram of the controller circuitry is presented in Fig. 3. The controller was attached to the chassis by using Phillips pan head metal screws $3 \mathrm{~mm}$ x $19.1 \mathrm{~mm}$ with nylon spacers $3 \mathrm{~mm} \times 4.8 \mathrm{~mm}$ between the circuit board and the chassis (Fig. 1).

\section{2) Wiring}

Cable staples (GB® PSW-100, Gardner Bender, Menomonee Falls, WI, USA) with wire nails $1.2 \mathrm{~mm}$ x 19.1 $\mathrm{mm}$ were used to secure all wires. The cable staples were sanded down until the wires were secure, but not too tight. The leads of the servos had to be extended, so the existing connectors were cut off, wires stripped, additional lengths of $0.20 \mathrm{~mm}^{2}$ insulated color coded stranded wire were soldered on, and the connections were insulated by using heat shrink tubing (1.6 $\mathrm{mm}$ diameter). The new wires were cabled together by using short lengths of heat shrink tubing $(2.4 \mathrm{~mm}$ diameter). After the proper length of the cable was determined, the cables were cut to length and the Molex ${ }^{\circledR}$ KK terminals were soldered on. The servo wires with terminals were then inserted in the correct order in the Molex ${ }^{\circledR}$ connector housing. The red servo wire was connected to positive supply voltage ( +5 volts), the black wire was connected to common, and the white servo wire was the signal wire and was connected to a $1 \mathrm{~K}$ ohm resister and then to the 16F628A PIC chip.

\section{3) Programming}

In order to program the $16 \mathrm{~F} 628 \mathrm{~A}$ PIC $®$ chip, the first step was to create the program or source code. This can be written using a simple text editor and saved (with the file extension "asm"). The next step was to assemble the source code into a hex file (with the file extension "hex") using an Assembler program. For this project, Microchip ${ }^{\circledR}$ 's Universal Assembler, MPASM $®$ v 03.20 was used, which is part of MPLAB® IDE v5.70.40 (available at:). The final step was to write the hex file into the 16F628A PIC $®$ chip using a PIC ${ }^{\circledR}$ programmer and software. For this project, EPICTM Plus for Windows PIC MCU Programmer version 2.43 and EPICTM Plus Programmer (parallel port interface) was originally used. Unfortunately the parallel port programmer was discontinued and the current product U2 Programmer 4.5 with USB port interface (available at: http://www.melabs.com) can be used.
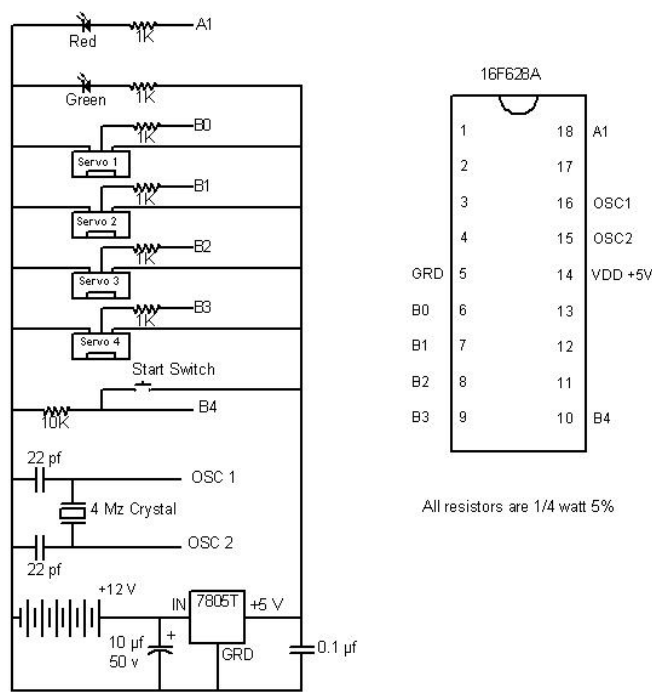

All resistors are $1 / 4$ watt $5 \%$

Fig. 3. Gas autosampler control circuit diagram. 
We note that the Basic Stamp® program used by Ginting et al. [4] was developed by a third party for $\$ 200$ and was not available. On the other hand, to encourage people to develop their own autosamplers, the source code and the hex code for the 16F628A PIC® chip is free and available upon request.

TABLE I: PARTS AND PRICES FOR CONSTRUCTION OF AUTOSAMPLERS USED WITH STATIC CHAMBERS FOR MEASUREMENT OF $\mathrm{N}_{2} \mathrm{O}$ EMISSIONS

\begin{tabular}{|c|c|c|c|}
\hline Parts & QTY/sampler & Price & Cat No (Vendor') \\
\hline \multicolumn{4}{|l|}{ Electronics } \\
\hline Crystal, Capacitors, Regulator, Resistors & 1 & $\$ 8.95$ & PPKIT (ME) \\
\hline Prototype Board & 1 & $\$ 9.95$ & PP18 (ME) \\
\hline 16F628A PIC® Chip & 1 & $\overline{\$ 2.08}$ & PIC16F628A-I/P-ND (DKE \\
\hline Green LED 2x5 mm & 1 & $\$ 0.38$ & 67-1046-ND (DKE) \\
\hline Red LED $2 \times 5 \mathrm{~mm}$ & 1 & $\$ 0.40$ & 67-1047-ND (DKE) \\
\hline Nylon Spacer \#4 x 3/16" (3 x 5 mm) & 4 & $\$ 0.38$ & 492-1073 (DKE) \\
\hline Heat Shrink Tubing 1/16" $(1.6 \mathrm{~mm}) \& 3 / 32 "(2.4 \mathrm{~mm})$ & as needed & $\$ 1.46$ & Q2F116/332B-NB (DKE) \\
\hline 18 Pin IC Socket & 1 & $\$ 0.17$ & $112231(\mathrm{JE})$ \\
\hline Tactile Switch SPST Momentary On & 1 & $\$ 0.39$ & $155256(\mathrm{JE})$ \\
\hline trip (makes 4) & 0.25 & $\$ 0$. & 2150 \\
\hline Molex@ Conn Housing 3 pos $2.54 \mathrm{~mm}$ & 4 & $\$ 1.00$ & $234801(\mathrm{JE})$ \\
\hline Molex@ Board Header 3 pos $2.54 \mathrm{~mm}$ & 4 & $\$ 0.76$ & 232274 (JE) \\
\hline Molex® Crimp Terminals KK 0.1" (2.54 mm) & 12 & $\$ 0.72$ & 234923 (JE) \\
\hline Molex Conn Molex Plug 2 pos $0.093^{\prime \prime}(2.36 \mathrm{~mm})$ & 1 & $\$ 0.25$ & 224071 (JE) \\
\hline Molex@ Power Connector Contact Male $0.093^{\prime \prime}(2.36 \mathrm{~mm})$ & 2 & $\$ 0.24$ & 224223 (JE) \\
\hline Molex Conn Molex Receptacle 2 pos $0.093^{\prime \prime}(2.36 \mathrm{~mm})$ & 1 & $\$ 0.25$ & 224143 (JE) \\
\hline \multirow{2}{*}{\multicolumn{4}{|c|}{ Resistors, 24 AWG $\left(0.20 \mathrm{~mm}^{2}\right)$ Bare Solid \& Insulated Stranded }} \\
\hline & & & \\
\hline & $(7,1,1)$ & $\$ 2.13$ & $690865(\mathrm{JE})$ \\
\hline \multicolumn{4}{|l|}{ rvo \& associated parts } \\
\hline Futaba $₫$ Servo $\$ 3003$ & 4 & $\$ 43.96$ & LXVW84 (TH) \\
\hline Dubro 670 Super Strength Long Arm Futaba $\circledast$ & 1 & $\$ 12.69$ & DUBM6670 (TH) \\
\hline Dubro Dura Collar 1/8" $(3 \mathrm{~mm})$ ID & 4 & $\$ 1.76$ & LXE106 (TH) \\
\hline Futaba $\circledast^{\circledR}$ Servo Grommet Round & 8 & $\$ 1.92$ & FUTM2310 (TH) \\
\hline Dubro Small Servo Mounting Hardware & 8 & $\$ 1.02$ & LXD647 (TH) \\
\hline \multirow{2}{*}{\multicolumn{4}{|c|}{ Hardware }} \\
\hline & & & \\
\hline Extension Spring $0.250^{\prime \prime} \times 0.0317^{\prime \prime} \times 4.00^{\prime \prime}(6 \times 0.8 \times 102 \mathrm{~mm})$ & 4 & $\$ 2.89$ & 9654K207 (MMC) \\
\hline Cable 18AWG/2 $\left(0.82 \mathrm{~mm}^{2}\right)$ Black SPT-1 $50 \mathrm{ft} @ \$ 0.24 / \mathrm{ft}$ & $0.9 \mathrm{~m}(3 \mathrm{ft})$ & $\$ 0.78$ & 8104K111 (MMC) \\
\hline \multirow{2}{*}{\multicolumn{4}{|c|}{$\mathrm{nm})$, \#10 $(5 \mathrm{~mm})$ plain, \#10 $(5 \mathrm{~mm})$ fende }} \\
\hline & & & \\
\hline (1) & various & $\$ 2.13$ & \\
\hline 2'x2'x11/16" (61x61x17.5 mm) Softwood Plywood A-B grade & $\begin{array}{c}1 \\
0.15 \mathrm{~m}(6\end{array}$ & $\$ 7.50$ & Local store \\
\hline 5/8" (16 mm) Dowel, 3/4" (19 mm) Pine, \& 3/4" (19 mm) Birch & in) & $\$ 2.00$ & Local store \\
\hline 1/4" (6mm) Cable Staples GB PSW-100 & 14 & $\$ 1.21$ & Local store \\
\hline Wire Nails \#17 x 3/4" (1.15 mm x $19 \mathrm{~mm})$ & 14 & $\$ 0.10$ & Local store \\
\hline Key Ring 1" (25 mm) & 4 & $\$ 2.60$ & Local store \\
\hline Screws \#4 (3 mm), \#6 (3.5 mm), \& \#8 (4 mm) & various & $\$ 1.63$ & Local store \\
\hline Plastic Syringes $(20 \mathrm{ml})$ & 4 & $\$ 2.50$ & 14-826-8 (Fisher) \\
\hline Check V & 4 & $\$ 8.93$ & AP13CVSXFSL (ARK-P) \\
\hline & 1 & $\$ 20.00$ & PS-1 \\
\hline \multirow{2}{*}{\multicolumn{4}{|c|}{$\begin{array}{l}\text { Battery Recharger } \\
\text { Programmer }\end{array}$}} \\
\hline & & & \\
\hline $\begin{array}{l}\text { U2 Programmer } 4.50 \text { with Accessories (including E } \\
\text { PIC® micro MCU Programmer v } 2.43)^{2}\end{array}$ & & 139.95 & U2CBUN (ME) \\
\hline
\end{tabular}

${ }^{1} \mathrm{ME}$, microEngineering Labs, Inc., Colorado Springs, CO, USA, www.melabs.com; DKE, Digi-Key® Electronics, Thief River Fall, MN, USA, www.digikey.com; JE, Jameco® Electronics, Belmont, CA USA, www.jameco.com; TH, Tower Hobbies®, Champaign, IL, USA, www.towerhobbies.com; MMC, McMaster-Carr ${ }^{\circledR}$, Los Angeles, CA, USA. www.mcmaster.com; Fisher, Fisher Scientific, Pittsburgh, PA, USA. www.fishersci.com; PS, Power Sonic, San Diego, CA, USA. www.power-sonic.com.

${ }^{2}$ One time purchase for all autosamplers.

\section{StATIC CHAMBERS, $\mathrm{N}_{2} \mathrm{O}$ EMISSION SAMPLING AND LABORATORY ANALYSIS}

The automatic sampler was used for $\mathrm{N}_{2} \mathrm{O}$ emission flux measurements in a pomegranate orchard where two irrigation systems and three nitrogen fertilizer application rates were investigated for water and $\mathrm{N}$ use efficiency. The static chamber was constructed based on the USDA Agricultural Research Service Greenhouse gas Reduction through Agricultural Carbon Enhancement network (GRACENet) protocols [5] with some modifications. The chamber was made from a commercially available $0.61 \mathrm{~mm}$ thick stainless steel steam table pan, which had nominal dimensions of 102 $\mathrm{mm} \times 324 \mathrm{~mm} \times 527 \mathrm{~mm}(\mathrm{H} \times \mathrm{W} \times \mathrm{D})$ (Update International, Los Angeles, CA, USA). A venting tube with a $3.2 \mathrm{~mm}$ inner diameter (ID) was installed through the chamber. A sampling port (stainless steel tubing with a $1.6 \mathrm{~mm}$ ID) was installed at the center of the chamber. Connection between the chamber and the four syringes through the check valve installed at the tip on the autosampler was made using Teflon® tubing (1.6 $\mathrm{mm}$ OD, $0.8 \mathrm{~mm}$ ID) through a perfusion manifold. A chamber base (collar) was made from the same product as the chamber by cutting $51 \mathrm{~mm}$ off from the bottom and with rim up was inserted into the soil to a depth of $25 \mathrm{~mm}$. An adhesive rubber tape (Rubber Weatherseal, $9.1 \mathrm{~mm} \mathrm{~W} \times 7.9 \mathrm{~mm} \mathrm{H}$, M-D Building Products, Oklahoma City, OK, USA) was installed along the rim of the chamber. When the chamber was placed on the base, both rims were fastened together using six large binder clips to ensure an air-tight seal.

\section{A. Sampling}

The closure of the chamber to the base was set to time 0 . An initial sample collected at time 0 would represent the background level. However, it is often difficult to do so if only one person is available to do the sampling and a timer can be used to wait for 30 or 60 seconds before starting the autosampler to withdraw the first gas sample from the chamber. Three subsequent samples were withdrawn at 30 minute intervals in our sampling until the fourth sample was withdrawn. This sampling schedule was observed with a linear increase in $\mathrm{N}_{2} \mathrm{O}$ concentration inside the chamber for most measurements in the pomegranate field. It should be noted that it is more important to obtain the linearity than having the background sample because calculation of flux is dependent on the slope or initial concentration increase with time.

\section{B. Sample Storage, Standard Preparation, Instrumental Analysis}

Upon completion of the sampling program by the autosampler, the $20 \mathrm{~mL}$ sample in the syringe can be removed and transferred to vials for instrumental analysis. We used 10 $\mathrm{mL}$ glass headspace vials (Agilent Technologies, Santa Clara, CA, USA) that were previously flushed with Ultra zero grade compressed air (Praxair, Fresno, CA, USA) and sealed with Teflon ${ }^{\circledR}$ faced butyl rubber septa secured with aluminum crimp seals to reduce the background $\mathrm{N}_{2} \mathrm{O}$ level. Nitrous oxide standards were prepared using the same procedure as the samples. Working $\mathrm{N}_{2} \mathrm{O}$ standards $(0,0.1,0.3$, and $1.0 \mu \mathrm{l}$ $\mathrm{L}^{-1}$ ) were first prepared by mixing $0.00,0.01,0.03$, and $0.10 \mathrm{~L}$ of $10 \mu \mathrm{L} \mathrm{L}^{-1} \mathrm{~N}_{2} \mathrm{O}$ standard (Air Liquid America Specialty Gases, Houston, TX, USA), with 1.00, 0.99, 0.97, and 0.90 L ultra-pure air, respectively, in $1 \mathrm{~L}$ Tedlar ${ }^{\circledR}$ bags. The standards in the unit of volume were first converted to mass concentration (e.g., ng $\mathrm{N}_{2} \mathrm{O}-\mathrm{N} \mathrm{cm}^{-3}$ ) for processing flux. Then $20 \mathrm{~mL}$ of the standards were withdrawn and injected into 10 $\mathrm{mL}$ individual glass vials. Before analysis, the pressure of sample or standard vials was released by quickly inserting and withdrawing a syringe needle $(0.7 \mathrm{~mm} \times 25 \mathrm{~mm})$. The release of the vial pressure was found to give more reproducible results compared to analysis directly from the pressurized vials.

The $\mathrm{N}_{2} \mathrm{O}$ concentration in the $10 \mathrm{~mL}$ glass headspace vials was analyzed on a gas chromatograph (GC) Agilent Technologies 6890N (Agilent Technologies, Santa Clara, CA, USA) equipped with a split/splitless inlet, a micro electron capture detector ( $\mu \mathrm{ECD})$, a headspace sampler (G1888) functioning as a gas autosampler connected to the $6890 \mathrm{~N} \mathrm{GC}$ using electronic pneumatics control (EPC), and a capillary column [HP-PLOT Q, $0.53 \mathrm{~mm}$ (ID) $\times 30 \mathrm{~m}$ (length) $\times 40 \mu \mathrm{m}$ (film thickness)]. Helium was the carrier gas and P-5 (a 
mixture of $5 \%$ methane and $95 \%$ argon) was the make-up gas for the detector. The GC inlet temperature was set at $35^{\circ} \mathrm{C}$. Using the split mode, the GC inlet pressure, split ratio, split flow, and total flow was $34.5 \mathrm{kPa}, 6: 1,24.3 \mathrm{ml} \mathrm{minute}^{-1}$, and $31.4 \mathrm{ml}$ minute $^{-1}$, respectively. The GC oven temperature was maintained at $30^{\circ} \mathrm{C}$ with a total run time of $5 \mathrm{~min}$. For the $\mu \mathrm{ECD}$, the temperature, mode, and combined flow were $350^{\circ} \mathrm{C}$, constant column + makeup flow, and $20.0 \mathrm{~mL} \mathrm{~min}{ }^{-1}$, respectively. The following parameters were used for the headspace sampler: sample loop size $(3 \mathrm{ml})$, sample loop temperature $\left(45^{\circ} \mathrm{C}\right)$, vial headspace pressure $(86.2 \mathrm{kPa})$, vial oven temperature (off), transfer line temperature (off), vial equilibrium time (1 $\mathrm{min})$, pressurization time $(0.5 \mathrm{~min})$, loop fill time $(0.5 \mathrm{~min})$, loop equilibrium time $(0.5 \mathrm{~min})$, injection time ( $1 \mathrm{~min}$ ), and shake setting (low). Under these conditions, the retention time for $\mathrm{N}_{2} \mathrm{O}$ was 3.7 min and the detection limit (three times of background noise level) was $0.03 \mu \mathrm{N} \mathrm{N}_{2} \mathrm{O} \mathrm{L}^{-1}$ or $0.034 \mathrm{ng} \mathrm{N}_{2} \mathrm{O}-\mathrm{N} \mathrm{cm}^{-3}$.

\section{Emission Flux Calculations}

Upon the closure of a static chamber, gas concentration inside the chamber headspace follows a linear increase within a certain period of time, i.e., with a constant diffusion rate. The length of this period is dependent on the characteristics and the concentration ingredients of the compound. The diffusion rate would decrease over time and when the linear model no longer applies, estimate of flux becomes more complicated. For measurements that do not fall into the linear range, non-linear models need to be used for flux calculations [6]-[8]. For this paper, we targeted emission measurement within the linear range for $\mathrm{N}_{2} \mathrm{O}$ concentration increase with time inside the chamber. The diffusion flux (f) into the chamber can be calculated as:

$$
f=\frac{V d C}{A d t}
$$

or

$$
f=b \frac{V}{A}
$$

where $\mathrm{b}\left(\mathrm{ng} \mathrm{N} \mathrm{N}_{2} \mathrm{O}-\mathrm{N} \mathrm{cm}^{-3} \mathrm{~h}^{-1)}\right.$ is the slope of a linear regression for $\mathrm{N}_{2} \mathrm{O}$ concentration ( $\mathrm{ng} \mathrm{N}_{2} \mathrm{O}-\mathrm{N} \mathrm{cm}^{-3}$ ) increase with time (h), $V$ is the chamber volume, $A$ is the surface area $\left(1440.4 \mathrm{~cm}^{2}\right)$ covered by the chamber, and V/A would be the effective chamber height. In our case, the effective chamber height $(12.7 \mathrm{~cm})$ included the chamber base height $(\sim 2.5 \mathrm{~cm})$ above soil for sealing the chamber on.

\section{Emission Measurement in a Pomegranate Field}

The pomegranate orchard where we measured $\mathrm{N}_{2} \mathrm{O}$ emissions was established to determine water and $\mathrm{N}$ use efficiencies from two irrigation systems and different $\mathrm{N}$ levels. The two irrigation treatments were surface drip irrigation (DI) and subsurface drip irrigation (SDI). The later was expected to yield high water and $\mathrm{N}$ use efficiencies with unknown effects on greenhouse gas such as $\mathrm{N}_{2} \mathrm{O}$ emissions. The autosampler and chamber described above were used to collect samples for $\mathrm{N}_{2} \mathrm{O}$ emissions from both irrigation methods and with two $\mathrm{N}$ application levels: $50 \%(\mathrm{~N} 1)$, and $100 \%$ (N2), Crop nitrogen requirements were determined based on biweekly (every 14 days) leaf sample analysis. We selected some data from the N1 and N2 treatments only in this paper. Detailed emission data and treatment effects in the pomegranate field are presented in another independent paper (Gao et al., manuscript is under preparation).

Measurements of $\mathrm{N}_{2} \mathrm{O}$ emissions were made both before and after fertilizer application in 2013. Selected data after fertilizer application are shown in Fig. 4. The data indicate that the autosampler worked very well by the linear increase of $\mathrm{N}_{2} \mathrm{O}$ concentration with correlation $\mathrm{r}^{2}>0.95$ most of the time except when emissions were substantially low. Prior to fertilizer application in spring 2013 (data not shown), $\mathrm{N}_{2} \mathrm{O}$ emission flux was low from all treatments (0 to $17.0 \mu \mathrm{g} \mathrm{m}^{-2}$ $\mathrm{h}^{-1}$ ). After fertilization began, significantly higher flux values were measured but with large differences between irrigation methods and $\mathrm{N}$ fertilizer application level. Fig. 4 illustrates that the DI resulted in much higher $\mathrm{N}_{2} \mathrm{O}$ flux values than the SDI. The higher level of $\mathrm{N}(\mathrm{N} 2)$ resulted in much higher $\mathrm{N}_{2} \mathrm{O}$ flux values than the lower $\mathrm{N}$ level (N1). The flux ranged from 4.1 to $8.8 \mu \mathrm{g} \mathrm{m}^{-2} \mathrm{~h}^{-1}$ for the SDI and 9.4 to $667.6 \mu \mathrm{g} \mathrm{m}^{-2} \mathrm{~h}^{-1}$ for the DI for the N1 and N2 treatments, respectively. Two years of field measurement data support this conclusion that is detailed in the paper by Gao et al. (manuscript is under preparation).
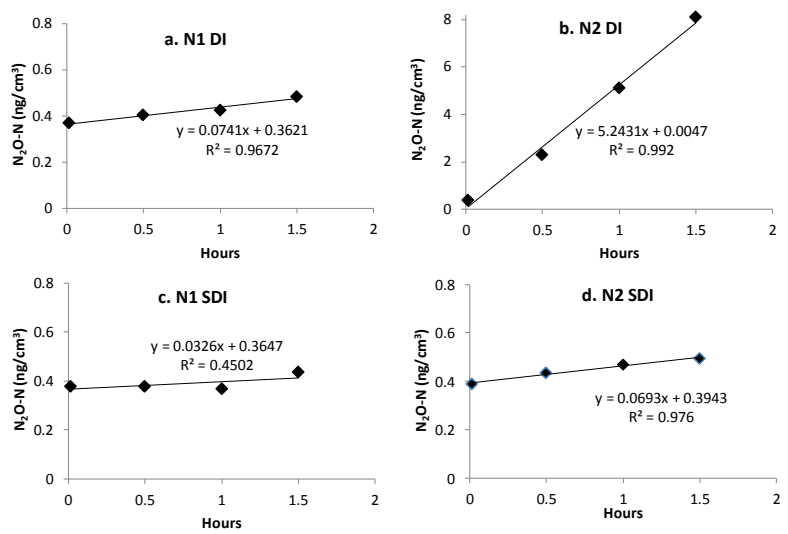

Fig. 4. Changes of $\mathrm{N}_{2} \mathrm{O}-\mathrm{N}$ concentration inside static chambers. The measurements were made on 29 May 2014, four weeks after fertilizer application began durign the growing season in a pomegranate orchard. DI, drip irrigation, SDI; subsurface drip irrigation; N1, nitrogen applied at 50\% of crop requirement; N2, nitrogen applied at $100 \%$ of crop requirement.

\section{IMPROVEMENT AND FURTHER CONSIDERATIONS}

The design of the autosampler has the flexibility for changes to be made for researchers depending on their needs and resources. 1). The open chassis design can be easily improved by placing into a container with lid to prevent potential water/rain, dust, or transportation damage. This may be especially necessary in areas with rain or strong wind/dust. 2). The paper provides a basis for constructing a sampler, which means one has many options to select parts. 3). The sampling syringe size can be changed based on sampling needs. The syringe mounting block would subsequently be modified during drilling and cutting to secure the syringe. 4 . Costs for constructing the autosamplers can vary significantly depending on the resources. If everything can be made in house, the total costs for one sampler is less than \$200 including the battery and recharger but excluding labor costs. 
Thus, costs can go significantly higher if one has to rely on outside resources to construct the controller.

\section{CONCLUSION}

A simple and low cost automatic sampler is presented to assist emission sampling using static chamber. The sampler can significantly reduce the amount of work involved in manual sampling and also improve accuracy of sampling time. Compared to an existing automatic sampler designed by Ginting et al. [4], we used wood instead of Plexiglas ${ }^{\circledR}$ for construction material, an open chassis design instead of a box, and a completely new design for the electronics (controller). Construction of the wood mounting board can be made easily by someone with some skills/knowledge of woodworking. All parts can be purchased from either local stores or commercial sources. The design of the automatic samplers is relatively simple to make and further modifications can be made to meet the various needs in gas emission research.

\section{APPENDIX}

Procedures to operate the gas autosampler: The 16F628A PIC® chip was programmed to send control pulses to the servos via their white signal wires in order to perform the following action:

1) The technician will rotate the brass rods (triggers) to a near vertical position.

2) The technician will connect the 12 -volt battery power to the power cable. Two important things will happen when the power is first applied.

3) First, on power up, the green LED is turned on to indicate that power is reaching the circuit board.

4) Second, the red LED is turned on to indicate that the system is being initialized with the servos rotated to their home positions to allow for the syringes to be installed.

5) When the servos are all in their home position and the red LED is off, then the syringes are installed, the plunger spring extended, and the trigger rod rotated into position.

6) When the Start button is pushed, the 16F628A sends a train of pulses to the first servo, which then rotates the arm 90 degrees and releases the trigger rod.

7) The spring retracts the plunger and the first gas sample is taken by the first syringe.

8) Using the crystal to accurately record the time, the 16F628A then waits.

9) When 30 minutes has passed, the 16F628A sends a train of pulses to the second servo, which then rotates the arm 90 degrees and releases the trigger rod.

10) The spring retracts the plunger and the second gas sample is taken by the second syringe.

11) Using the crystal to accurately record the time, the 16F628A then waits.

12) The process is repeated for the third and fourth sample.

13) The red LED is turned off to indicate that the program is complete. Disconnect the power.

The 16F628A PIC® source code and the hex file are available upon request. Below is a simplified program.

Gas autosampler connected to battery turns on the Green Light Emitting Diode (LED)
Initialization started

1) Turn on the BUSY Red LED

2) Send 1 millisecond pulses to Servo 1 that rotate the arm to down position

3) Send 1 millisecond pulses to Servo 2 that rotate the arm to down position

4) Send 1 millisecond pulses to Servo 3 that rotate the arm to down position

5) Send 1 millisecond pulses to Servo 4 that rotate the arm to down position

6) Turn off the BUSY Red LED

Wait for the Start Switch to be depressed

Start Switch depressed and released

1) Turn on the BUSY Red LED

2) Send 2 millisecond pulses to Servo 1 that rotate the arm to up position

3) Wait 30 minutes

4) Send 2 millisecond pulses to Servo 2 that rotate the arm to up position

5) Wait 30 minutes

6) Send 2 millisecond pulses to Servo 3 that rotate the arm to up position

7) Wait 30 minutes

8) Send 2 millisecond pulses to Servo 4 that rotate the arm to up position

9) Turn off the BUSY Red LED

Program is complete

\section{NOTE}

Mention of trade names or commercial products in this publication is solely for the purpose of providing specific information and does not imply recommendation or endorsement by U.S. Department of Agriculture. USDA is an equal opportunity provider and employer.

\section{REFERENCES}

[1] S. Gao and D. Wang, "Vapor flux measurements - Chamber methods," Vapor Emission to Outdoor Air and Enclosed Spaces for Human Health Risk Assessment: Site Characterization, Monitoring and Modeling, Nova Science Publishers, Inc., Hauppauge, NY, USA, ch. 9, pp. 191-207, 2011.

[2] G. P. Livingston and G. L. Hutchinson, "Enclosure-based measurement of trace gas exchange: applications and sources of error," Methods in Ecology. Biogenic Trace Gases: Measuring Emissions from Soil and Water, Blackwell Sci., London, pp. 14-51, 1995.

[3] S. Nishimura, S. Sudo, H. Akiyama, S. Yonemura, K. Yagi, and H. Tsuruta, "Development of a system for simultaneous and continuous measurement of carbon dioxide, methane and nitrous oxide fluxes from croplands based on the automated closed chamber method," Soil Sci. Plant Nutr., vol. 51, pp. 557-564, 2005.

[4] D. Ginting, S. L. Arnold, N. S. Arnold, and R. S. Tubbs, "Construction and testing of a simple and economical soil greenhouse gas automatic sampler," J. Plant. Nutr., vol. 30, pp. 1441-1454, 2007.

[5] T. B. Parkin and R. T. Venterea. "Chamber-based trace gas flux measurements," Sampling Protocols, ch. 3, pp. 3-1 to 3-39, 2010.

[6] G. L. Hutchinson and A. R. Mosier. "Improved soil cover method for field measurement of nitrous oxide fluxes," Soil Sci. Soc. Am. J., vol. 45, pp. 311-316, 1981.

[7] S. W. Wagner, D. C. Reicosky, and R. S. Alessi, "Regression models for calculating gas fluxes measured with a closed chamber," Agron J., vol. 89, pp. 279-284, 1997.

[8] S. Gao, A. Hendratna, Z. Cai, and C. Phene, "Effects of irrigation methods and nitrogen fertilizer application rate on $\mathrm{N}_{2} \mathrm{O}$ emissions in a pomegranate orchard," Int. J. Environ. Sci. Devel. 


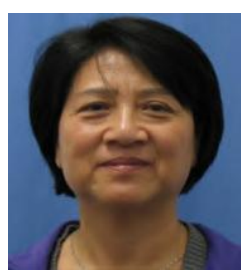

Suduan Gao is a research soil scientist in USDA ARS, SJVASC, Water Management Research Unit, located at Parlier, CA, USA. She received her MS degree in Chinese academy of agricultural sciencies in 1985 and Ph.D in soil science from Universitiy of California Davis (US Davis) in 1992. Following her Ph.D, she conducted 12 years of environmental research in UC David as a postodoc and an independent researcher. In 2004, Dr. Gao joined USDA-ARS and has been conducting research on fumigant emission reduction and efficacy as well as increasing agrochemical (e.g., nitrogen fertilizer) use efficiency and reduce environmental impact.

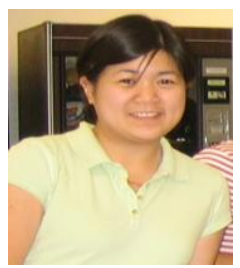

Aileen Hendratna received her MS degree in water system technology from Royal Institute of Technology, Stockholm, Sweden in 2011 and BS degree in soil and water science from University of California Davis in 2004. She is a Biological Science Technician in USDA, ARS, SJVASC, Water Management Research Unit located at Parlier, CA, USA.

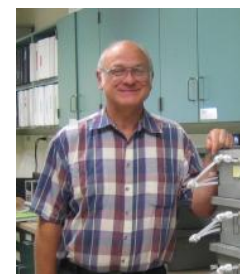

Tom Pflaum received his MS degree in chemistry from California State University, Fresno in 1979 and BS degree in chemistry from California State University, Fresno in 1975. His current position is Specialist/Chemist Emeritus with the USDA, ARS, SJVASC, Water Management Research Unit, located at Parlier CA, USA starting in 2011. Previously, he was an Analytical Chemist/Support Scientist at Water Management Research Unit from 1987 to his early retirement in 2011. He was employed as Director of Quality Control/Analytical Chemist in a pharmaceutical Manufacturing firm from 1979 to 1987. 